\title{
Human cutaneous B cells: what do we really know?
}

\author{
Irina Lerman ${ }^{1}$, Drew C. Mitchell ${ }^{1}$, Christopher T. Richardson ${ }^{2,3}$ \\ ${ }^{1}$ University of Rochester School of Medicine and Dentistry, Rochester, NY, USA; ${ }^{2}$ Department of Dermatology, University of Rochester Medical \\ Center, Rochester, NY, USA; ${ }^{3}$ Division of Allergy, Immunology and Rheumatology, University of Rochester Medical Center, Rochester, NY, USA \\ Contributions: (I) Conception and design: CT Richardson; (II) Administrative support: CT Richardson; (III) Provision of study materials or patients: \\ None; (IV) Collection and assembly of data: None; (V) Data analysis and interpretation: None; (VI) Manuscript writing: All authors; (VII) Final \\ approval of manuscript: All authors. \\ Correspondence to: Christopher T. Richardson, MD, PhD. Department of Dermatology, University of Rochester Medical Center, 601 Elmwood Ave, \\ Box 697, Rochester, NY 14642, USA. Email: crichardson@urmc.rochester.edu.
}

\begin{abstract}
B cells play many critical roles in the systemic immune response, including antibody secretion, antigen presentation, $\mathrm{T}$ cell co-stimulation, and pro- and anti-inflammatory cytokine production. However, the contribution of $\mathrm{B}$ cells to the local immune response in many non-lymphoid tissues, such as the skin, is incompletely understood. Cutaneous B cells are scarce except in certain malignant and inflammatory conditions, and as such, have been poorly characterized until recently. Emerging evidence now suggests an important role for cutaneous B in both skin homeostasis and pathogenesis of skin disease. Herein, we discuss the potential mechanisms for cutaneous B cell recruitment, localized antibody production, and $\mathrm{T}$ cell interaction in human skin infections and primary skin malignancies (i.e., melanoma, squamous cell carcinoma). We further consider the likely contribution of cutaneous B cells to the pathogenesis of inflammatory skin diseases, including pemphigus vulgaris, lupus erythematosus, systemic sclerosis, hidradenitis suppurativa, and atopic dermatitis. Finally, we examine the feasibility of B cell targeted therapy in the dermatologic setting, emphasizing areas that are still open to investigation. Through this review, we hope to highlight what we really know about cutaneous B cells in human skin, which can sometimes be lost in reviews that more broadly incorporate extensive data from animal models.
\end{abstract}

Keywords: B cell; B cell depletion therapy (BCDT); pemphigus vulgaris (PV); lupus; systemic sclerosis

Submitted Jul 07, 2020. Accepted for publication Sep 04, 2020.

doi: $10.21037 /$ atm-20-5185

View this article at: http://dx.doi.org/10.21037/atm-20-5185

\section{Introduction}

The integrity of the cutaneous barrier against microbial and viral pathogens is dependent on the ability to mount both innate and adaptive immune responses. Healthy human skin is composed of an intricate network of immune cells known as the "skin immune system" (SIS), which has been extensively described and reviewed elsewhere (1). Briefly, Langerhans cells (LCs) and dermal dendritic cells (dDCs) patrol and sample the epidermal and dermal milieu. During infection or inflammation, LCs and dDCs migrate to draining lymph nodes (dLNs) (2) where they function as antigen presenting cells (APCs) and stimulate naïve $\mathrm{T}$ cell polarization and expansion, thereby facilitating an inflammatory cascade (1). In both inflamed and noninflamed tissue, the majority of cutaneous lymphocytes are tissue resident memory $\left(\mathrm{T}_{\mathrm{RM}}\right) \mathrm{T}$ cells, uniquely capable of producing rapid, local immune responses without egression to secondary sites (3).

Conversely, the number of B cells in healthy human skin is relatively small (4), making the study of cutaneous $\mathrm{B}$ cells quite difficult. It is primarily for this reason that these cells are so poorly characterized and their role in skin immunity and disease largely unknown. Two recent 
reviews do an excellent job of summarizing various studies of systemic and cutaneous B cells in skin immunity, with an emphasis on animal models $(5,6)$. However, definitive data concerning cutaneous B cells in humans are quite limited. Therefore, the purpose of this review is different; we hope to delineate what we really know and what we do not know about cutaneous B cells in humans. Human investigation is critical, especially in light of the many differences that exist in both B cell and skin biology among animal models, and between animals and humans (7). Given the paucity of human studies on this subject, we will also discuss the next steps in bridging this gap in knowledge. Importantly, we emphasize areas requiring further investigation and discuss the therapeutic implications of systemic and localized B cell depletion as it relates to the field of dermatology.

We present the following article in accordance with the Narrative Review reporting checklist (available at http:// dx.doi.org/10.21037/atm-20-5185).

\section{Cutaneous B cells in healthy human immunity}

Until recently, B cells were not thought to be part of the normal skin immune repertoire $(5,6)$. Whether cutaneous B cells are truly tissue-resident or merely circulating and migratory is not known, nor are the mechanisms for such recruitment to human skin well defined. Different mechanisms have been proposed as to how B cells migrate to skin in ovine (CCR6-CCL20 dependent) and murine ( $\alpha 4 \beta 1$ integrin and BAFF dependent) models $(8,9)$. Involvement of cutaneous lymphocyte antigen (CLA) is also possible, given its importance for $\mathrm{T}$ cell trafficking to the skin (3). Indeed, B cells expressing CLA circulate in peripheral blood of both healthy individuals and those with cutaneous disease $(10,11)$. Furthermore, CLA expression is upregulated by lesional B cells of patients with pemphigus vulgaris (PV), suggesting skin-homing capability (11). While direct involvement is still under investigation, additional chemokine receptors potentially responsible for cutaneous recruitment of B cells include CCR4, CCR5, CCR7, CCR10, CXCR3, CXCR4, and CXCR5 (Figure 1) (11).

B cells play many roles in the adaptive immune system, including antibody secretion, antigen presentation, $\mathrm{T}$ cell co-stimulation, and pro- and anti-inflammatory cytokine production. The evidence for cutaneous B cells performing these functions in human skin is limited, though growing. For many years it has been known that IgM, IgG, and IgA antibodies encase bacteria and fungi isolated from human skin and interfere with their infectious properties
(Figure 1) (12). However, antibody was not thought to be present in abundance in healthy skin, except in human sebaceous and eccrine sweat glands where secretory IgA is detectable $(13,14)$. Furthermore, given the paucity of B cells in healthy skin, cutaneous antibody deposition was considered to derive primarily from systemic sources. However, recent reports demonstrate that cutaneous antibody can be produced locally in healthy skin. B cells are detectable by immunohistochemistry and flow cytometry in normal human skin and produce various IgG subclasses, including IgG1, IgG2, and IgG3 (10). In addition, $\operatorname{Ig} M$ antibody secreting cells (ASCs) are similarly ubiquitously detectable in healthy skin, further supporting a role for cutaneous B cells in maintaining human skin immunity against pathogens (9). It is therefore not surprising that B cell and ASC infiltrates are prominent in infectious skin lesions of leprosy, syphilis, and leishmaniasis (15-17). In lepromatousspectrum skin disease, in-situ IgG antibody production has been demonstrated (15). In secondary syphilis, opsonic antibodies appear necessary for macrophage-mediated T. pallidum clearance (16), though evidence of local antibody production is lacking. Late cutaneous leishmaniasis lesions exhibit plasma cell predominance over B cells, suggestive of lesional maturation and possible local immunoglobulin secretion (17).

In addition to antibody production, cutaneous B cells may contribute to local infectious and inflammatory responses via the development and maintenance of granulomas, since B cell deficient individuals with $\mathrm{X}$-linked agammaglobulinemia are unable to form granulomas (18). In both infectious and non-infectious granulomas, B cells and plasma cells are present at the periphery, an area with a prominent pro-inflammatory cytokine milieu (i.e., IL-1, IL-6, TNF- $\alpha$ ) (Figure 1) $(18,19)$. In cutaneous leishmaniasis, infiltrating B cells positively correlate with the number of inflammatory granulomas (20). This spatial relationship between B cells, plasma cells, granulomas, and proinflammatory cytokines provides further, albeit indirect, evidence for cutaneous B cell involvement in granuloma formation.

Evidence for anti-tumor immunity is more definitive. Increased numbers of infiltrating CD $20^{+} \mathrm{B}$ cells and elevated CD20 mRNA expression in melanoma lesions correlates with improved patient survival $(10,21)$. Cutaneous $\mathrm{B}$ cells are organized in follicle-like aggregates in a subset of melanoma tumors-reminiscent of tertiary lymphoid organ (TLO)-like structures present in various other organs 


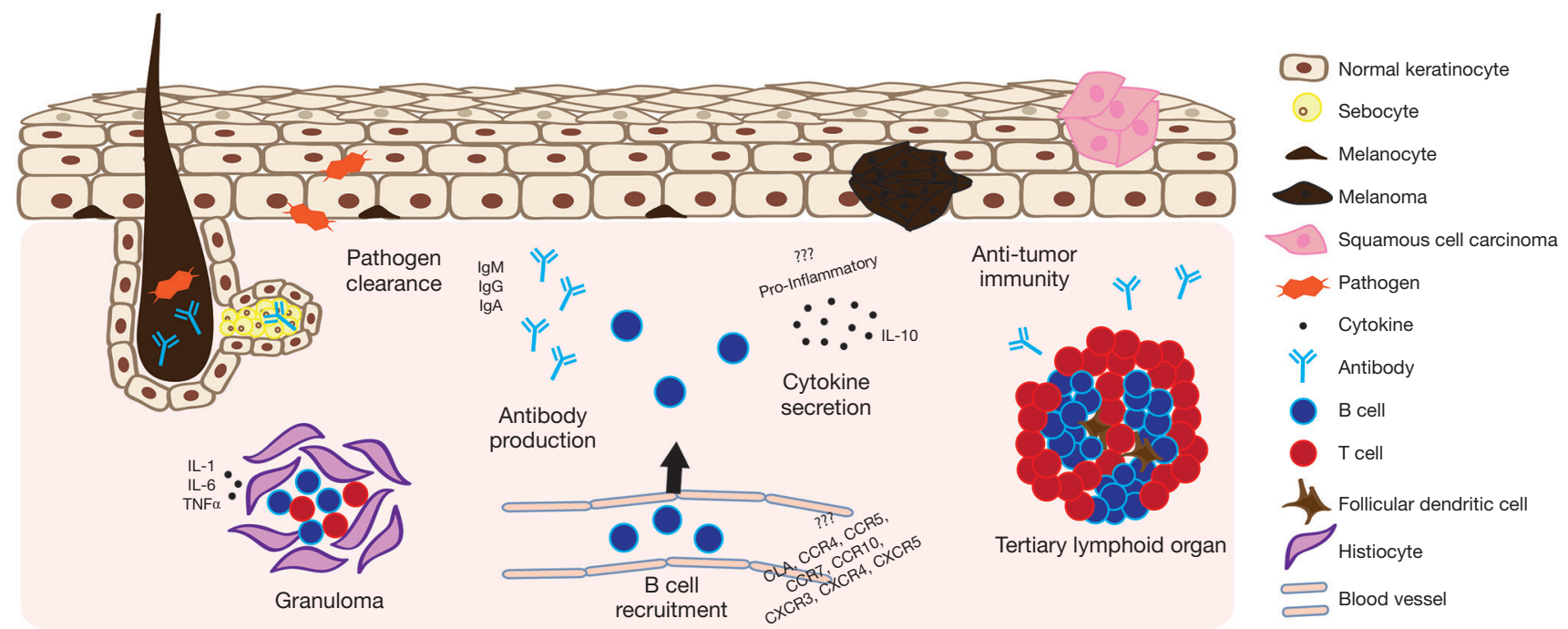

Figure 1 Cutaneous B cells in healthy human immunity. The mechanisms of B cell recruitment to the skin during homeostatic and pathologic conditions is still under investigation but may involve cutaneous lymphocyte antigen (CLA), CCR4, CCR5, CCR7, CCR10, CXCR3, CXCR4, and CXCR5. Localized actions of cutaneous B cells include antibody production (i.e., IgM, IgG, IgA) and cytokine secretion (i.e., IL-10), which promote pathogen clearance and anti-tumor immunity. Cutaneous B cells further organize within granulomas and tertiary lymphoid organs (TLOs), closely associated with T cells.

affected by chronic inflammation. Moreover, B cells closely associated with activated $\mathrm{T}$ cells confer better prognosis in melanoma, indicating that their interaction is necessary for effective anti-tumor immunity (22). These cell aggregates suggest the possibility of $\mathrm{B}$ cell help to anti-tumor $\mathrm{T}$ cells via antigen presentation or co-stimulation, though $\mathrm{T}$ cell help for B cell production of anti-tumor antibody is also possible. Indeed, two recent studies by Helmink et al. and Cabrita et al. propose that B cell-rich TLOs directly enhance $\mathrm{T}$ cell-mediated therapeutic response to immune checkpoint blockade (ICB) in patients with both high-risk primary and metastatic melanoma $(23,24)$. Specifically, $\mathrm{B}$ cell and TLO densities are significantly increased in ICB responders compared to non-responders, conferring improved overall survival. Transcriptional analysis not only confirms intra-tumoral enrichment of B cell-related genes and activated $\mathrm{T}$ cell markers in ICB responders, but also reveals increased $\mathrm{B}$ cell receptor (BCR) diversity and clonal immunoglobulin heavy and light chain expression, supporting a critical role for B cells in anti-melanoma immunity within the skin $(23,24)$. Of note, the presence of plasma cells alone, without significant B or T cell infiltrate, is associated with poor survival in melanoma (25). These data support the idea that antibody secretion, without apparent $\mathrm{B}$ and $\mathrm{T}$ cell interaction, TLO formation, and/ or cytokine production, is insufficient for immune-driven tumor clearance (Figure 1).

Similarly, human cutaneous squamous cell carcinoma (cSCC) exhibits enhanced B cell infiltration and immunoglobulin deposition compared to normal tissue (26). Longstanding B cell depletion with the anti-CD20 monoclonal antibody rituximab may also promote development of cSCC (27). Interestingly, immunosuppressed organ transplant recipients demonstrate reduced numbers of infiltrating B cells within the cSCC tumor, at the invasive margin, and the surrounding non-malignant skin compared to immunocompetent controls (28). Therefore, it is possible that cutaneous B cell impairment contributes to increased risk of cSCC development in immunosuppressed individuals, although this remains to be tested.

Despite the evidence for cutaneous B cells as protective agents in skin malignancy, there are contrasting data to suggest that infiltrating B cells can also contribute to tumor immune evasion, potentially indirectly through polarization of tumor-associated myeloid cells or directly via the production of the anti-inflammatory cytokine IL-10 (26,29). IL-10 secreting B cells have also been found in normal human skin (30), as well as in cutaneous lupus (31). The fact that IL-10 secreting B cells have been found in the different 


\section{Page 4 of 9}

contexts of normal skin, malignancy, and autoimmunity suggests a more global regulatory role for at least a subset of cutaneous B cells. In contrast, while B cells are known to secrete inflammatory cytokines (32), this ability has not yet been described in human cutaneous B cells (Figure 1).

In summary, B cells are present in human skin, albeit in small numbers. The details of how they migrate to the skin are not fully known, though CLA appears to be important, and murine and ovine models offer different possibilities to explore. Cutaneous B cells can produce antibody locally, though its relevance in immunity to infection has not been definitively established. They also appear to interact with $\mathrm{T}$ cells in cutaneous tumor surveillance, though our understanding of this interaction is limited, and further characterization of their ability to present antigen or provide $\mathrm{T}$ cell help is needed. Certainly, ovine cutaneous $\mathrm{B}$ cells are well-equipped for local antigen presentation, as they highly express MHCII, CD1, and CD80/86 (8). Data on cytokine production by cutaneous B cells thus far are limited to the regulatory cytokine IL-10. Further characterization of human cutaneous B cells in healthy skin immunity will be critical as we attempt to also understand their pathogenic role in skin disease (Figure 1).

\section{The pathogenic role of cutaneous B cells in human disease}

While our understanding of B cells in healthy human skin is limited, a growing body of literature supports their potential role in a variety of skin pathologies. These include cutaneous B cell malignancy, inflammatory skin disease, connective tissue disease, and immunobullous disorders. A discussion of cutaneous B cell malignancy is beyond the scope of this review and is reviewed elsewhere; however, this section will highlight a few common skin diseases in which cutaneous B cells are prevalent and may contribute to pathogenesis.

$\mathrm{PV}$ is an autoimmune blistering skin disease caused by aberrant autoantibody production against the desmosomal cadherins, desmolgein-1 (Dsg1) and desmoglein-3 (Dsg3), expressed by epidermal keratinocytes (Figure 2). While it has long been known that circulating autoantibodies correlate with and contribute to PV severity, the role of cutaneous B cells in PV was only recently elucidated $(11,33)$. Yuan et al. elegantly demonstrate an influx of Dsg1/3-specific B cells in lesions of PV patients compared to skin of healthy controls. Cutaneous B cells derived from $\mathrm{PV}$ lesions and cultured ex vivo produce copious amounts of anti-Dsg1 and anti-Dsg3 antibodies, correlating with disease severity. B cells derived from peripheral blood of PV patients, however, lack this response. Histologically, skin infiltrating $\mathrm{B}$ cells aggregate with $\mathrm{CD}^{+} \mathrm{T}$ cells to form TLOs (Figure 2) (33), which contain centroblasts, plasmablasts, and plasma cells, indicative of in situ B cell differentiation (11). Furthermore, B cells isolated from these structures highly express B lymphocyteinduced maturation protein-1 (BLIMP-1), interferon regulatory factor 4 (IRF4), and B cell lymphoma 6 (BCL-6)-transcription factors that are crucial for B cell differentiation and germinal center formation (11). Accordingly, PV lesional B cells exhibit BCR enrichment compared to peripheral B cells, indicating local clonal expansion (11). These landmark findings demonstrate for the first time a clear pathogenic role for cutaneous B cells in a non-malignant skin disease.

Lupus erythematosus (LE) is a heterogeneous systemic autoimmune disease defined by loss of central tolerance, abnormal $\mathrm{T}$ and $\mathrm{B}$ cell activation, autoantibody production, and chronic end-organ inflammation with prominent mucocutaneous involvement. Indeed, direct immunofluorescence (DIF) of cutaneous lesions reveals immunoglobulin deposition at the dermal-epidermal junction (DEJ), known as the lupus band test (LBT) (Figure 2). However, a positive LBT may also be present in clinically normal skin of patients with systemic lupus erythematosus (SLE) (34); therefore, unlike in PV, antibody does not appear sufficient to drive skin pathology, which calls into question its importance in disease pathogenesis. While it has been assumed that the antibody deposited at the DEJ derives from the peripheral blood, the aforementioned studies in PV suggest that it may be produced locally, especially when considering that some cutaneous lupus lesions demonstrate a prominent B cell infiltrate (Figure 2).

Skin lesions of discoid lupus erythematosus (DLE), the most common form of cutaneous lupus, reveal enhanced infiltration of B cells at the DEJ, perivascular, and periadnexal regions compared to normal skin, lichen simplex chronicus (LSC), and lichen planus (LP) (35). Enhanced B cell infiltration appears to be accompanied by $\mathrm{CD}^{+}, \mathrm{CD}^{+}$, and $\mathrm{CD}^{+}{ }^{+} \mathrm{T}$ cells (36). Moreover, B cells organize into aggregates, closely associated with $\mathrm{CD}^{+}$ $\mathrm{T}$ cells (37). Nests of B cells and plasma cells in close proximity to $\mathrm{T}$ cells are also found in the lesional skin of patients with LE panniculitis (38). While reminiscent of the TLOs observed in cutaneous melanoma and PV, the 


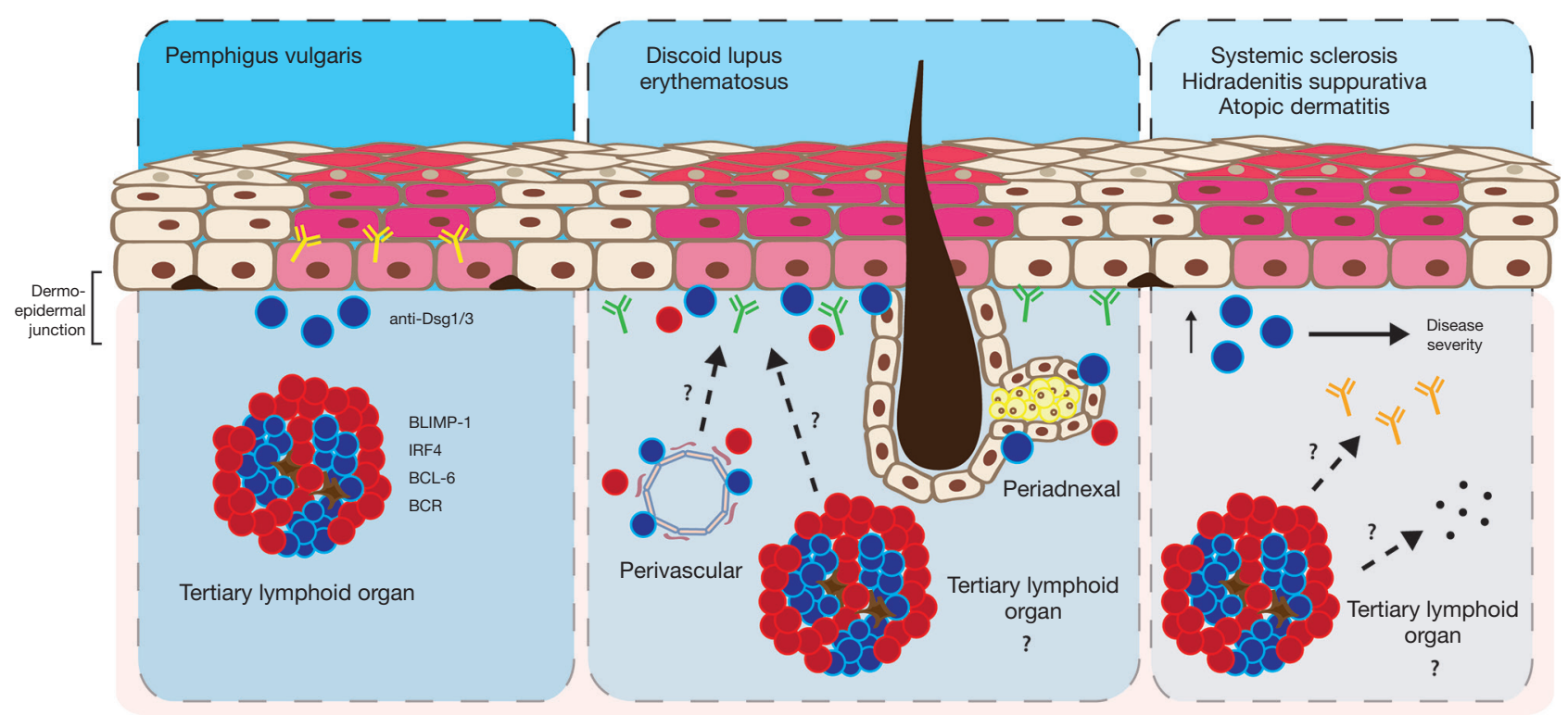

Figure 2 Cutaneous B cells in disease pathogenesis. Pemphigus vulgaris (PV) exhibits the most direct evidence for pathogenic cutaneous B cells via localized production of desmosomal targeting antibodies (anti-Dsg1/3). Cutaneous B cells aggregate with $\mathrm{T}$ cells to form tertiary lymphoid organs (TLOs), where they undergo transcription factor upregulation (i.e., BLIMP-1, IRF4, BCL-6) and B cell receptor (BCR) enrichment to facilitate local B cell differentiation and clonal expansion, respectively. In lupus erythematosus (LE), autoantibodies are deposited at the dermo-epidermal junction (DEJ) within both clinically affected and unaffected skin. Unlike in PV, the source (i.e., local vs. systemic B cells) and pathogenic role for these autoantibodies have yet to been established. In discoid LE, enhanced infiltration of B cells is observed at the DEJ, perivascular, and periadnexal regions. Moreover, structures reminiscent of TLOs are observed, though their pathogenic role is unclear. Enhanced cutaneous B cell infiltration is also apparent in systemic sclerosis, hidradenitis suppurativa, and atopic dermatitis, and is correlated with skin disease severity. However, a direct pathogenic mechanism via autoantibody production or cytokine secretion is still unknown.

potential role of these lymphoid aggregates in cutaneous lupus has not been evaluated, and it is unknown if these structures produce antigen-specific B cells or pathogenic antibody (Figure 2). Evaluation of the B and T cell infiltrate in DLE lesions at different stages revealed CD20 $0^{+} \mathrm{B}$ cell and $\mathrm{CD} 138^{+}$plasma cells present in both scarred and nonscarred inflammatory lesions, though more enriched in lesions with scarring. This is in contrast to $\mathrm{CD}^{+} \mathrm{T}$ cells, which were enriched in lesions without scarring. Since scar formation is a characteristic feature of DLE progression, the authors proposed a role for $\mathrm{CD} 8^{+} \mathrm{T}$ cells and $\mathrm{CD} 20^{+} \mathrm{B}$ cells in disease initiation and propagation, respectively (39). Complementing the preceding immunohistochemical studies, transcriptomic analyses confirm enriched gene signatures of B cell activation and leukocyte chemotaxis in chronic cutaneous LE (CCLE) lesions compared to normal controls (40). While there is much to suggest a prominent role for B cells in DLE pathogenesis, definitive studies are lacking.

B cells have also been studied in systemic sclerosis (SSc), an autoimmune disease marked by limited or diffuse cutaneous fibrosis. Numerous analyses of immune infiltrates in human SSc skin reveal elevated numbers of cutaneous $\mathrm{CD} 20^{+} \mathrm{B}$ cells and $\mathrm{CD} 138^{+}$plasma cells compared to healthy tissue $(41,42)$. Transcriptomic data further support the prominence of B cells and plasma cells in skin isolated from patients with SSc $(43,44)$. B cells are present in both uninvolved skin and early SSc and correlate with disease progression, suggesting contribution to lesion development (42). This may be secondary to localized cytokine or antibody production leading to collagen deposition and fibrosis (Figure 2) (45).

Conspicuous infiltration of $\mathrm{B}$ cells was recently identified in hidradenitis suppurativa (HS), a chronic inflammatory condition that affects apocrine sweat glands and results in disfiguring scar formation. Specifically, both B cells and 
plasma cells are increased in early and chronic HS compared to both perilesional skin and healthy controls. Moreover, B cells form follicle-like structures within the dermis, suggestive of ectopic germinal centers (46). Most recently, an abnormally activated humoral response and resultant dermal damage was proposed in the pathogenesis of HS, predominantly due to the abundance of immunoglobulin and plasma cell associated gene signatures (Figure 2) (47).

Intriguingly, a recent analysis of blood and skin from patients with atopic dermatitis (AD) revealed possible B cell aberrancy in a primarily $\mathrm{T}$ cell mediated disease. In particular, B cells accumulate in $\mathrm{AD}$ lesions and predict worse disease severity, while a subset of B cells, including $\mathrm{CD} 27^{+}$memory B cells and $\mathrm{CD} 38^{+}$plasmablasts, accumulate peripherally (Figure 2) (48). To date, plasma cells have not been identified in the cellular infiltrate of $\mathrm{AD}$ lesions.

In summary, cutaneous B cells accumulate locally in several human immunobullous, autoimmune, and inflammatory skin conditions, including PV, DLE, SSc, $\mathrm{HS}$, and $\mathrm{AD}$. However, with the exception of PV, in which a clear autoantibody-mediated role has been identified, much less is known about the functional role of B cells in other skin diseases. As in PV, B cells aggregate with T cells to form TLO-like structures in DLE and possibly HS, suggesting localized immune response (Figure 2). In some skin diseases, B cell accumulation correlates with disease activity, but whether or not this B cell infiltrate is pathogenic, immunoregulatory, or merely a side effect of more general inflammation remains to be determined.

\section{Cutaneous B cell targeted therapy in dermatologic disease}

It is well known that systemic B cell depletion therapy (BCDT) with rituximab leads to impressive clinical response and profound reduction in anti-Dsg antibody titers in patients with refractory PV (49). Given the aforementioned contribution of infiltrating $\mathrm{B}$ cells to $\mathrm{PV}$ pathogenesis, it is tempting to speculate whether preferentially targeting the cutaneous B cell population would be similarly as efficacious. Indeed, direct intralesional injection of reduced-dose rituximab results in clinical remission of refractory oral PV, although this effect cannot be definitively attributed to depletion of cutaneous B cells, since circulating B cells are also reduced (50). A subsequent study revealed comparable efficacy of intralesional rituximab and intralesional triamcinolone in the treatment of refractory PV, although the potential effect on peripheral $\mathrm{B}$ cells was not evaluated (51). Collectively, these findings emphasize the feasibility and encourage the development of localized or topical BCDT for PV.

BCDT with rituximab has also been evaluated in cutaneous lupus, with promising but somewhat mixed results $(52,53)$. While BCDT effectively depletes circulating $\mathrm{B}$ cells, it might not always adequately reduce pathogenic B cells in tissue (54). Therefore, residual pathogenic cutaneous $\mathrm{B}$ cells may explain the variability in responsiveness of skin lesions to BCDT. Likewise, B cell activating factor (BAFF) inhibition with belimumab was recently shown to be particularly efficacious in the treatment of recalcitrant cutaneous lupus (55). Mouse models demonstrate cutaneous ASC survival to be BAFF-dependent, and BAFF appears to be upregulated in human DLE skin $(9,56)$. However, whether belimumab targets cutaneous B cells specifically is still unknown. Overall, the significant B cell infiltrate in cutaneous lupus makes local B cell targeted therapy (as in PV) an intriguing therapeutic option that is still open to investigation.

In patients with SSc treated with belimumab, clinical improvement correlates with the reduction of cutaneous expression of genes related to $\mathrm{B}$ cell activation and fibrosis (57). However, as in cutaneous lupus, the efficacy of anti-CD20 BCDT in SSc is mixed, despite effective depletion of both peripheral and dermal $\mathrm{B}$ cell populations $(58,59)$. This inconsistent efficacy in SSc may be due to the relatively greater importance of plasma cells, which do not express CD20, and are thus resistant to rituximab. Indeed, SSc patients treated with the anti-CD19 monoclonal antibody inebilizumab have decreased cutaneous plasma cell gene signatures and collagen secretion (44). CD19 is expressed on a somewhat wider array of B cells than CD20, including plasmablasts and some plasma cells. Furthermore, greater clinical improvement in response to treatment was seen in patients with high baseline plasma cell gene signatures as compared to low, pointing to a predominantly plasma cell driven pathology (44).

Lastly, as described in the previous section, studies of cutaneous B cells in HS and AD are scant. As such, only one case report demonstrates successful treatment of HS with rituximab (60). Similarly, there is limited data on the efficacy of rituximab in AD (61). Thus, future controlled trials are needed to establish utility of both systemic and localized B cell depletion in these skin diseases.

\section{Bridging the gap}

In conclusion, emerging evidence supports a role for 
human cutaneous B cells in both homeostasis and disease. Thorough immunophenotyping and functional studies are required for further characterization of infiltrating $\mathrm{B}$ cells and to distinguish between resident and transient populations. Importantly, how human cutaneous B cells interact with other immune cell types in the dermal network to carry out local effector functions such as antibody and cytokine production is largely unknown. Work performed in various animal models is informative and will help to direct future studies. Finally, as we learn more about the role of B cells in skin immunity and disease, skin-directed B cell targeted therapy may emerge as an important and more personalized approach in dermatologic disease management.

\section{Acknowledgments}

Funding: None.

\section{Footnote}

Provenance and Peer Review: This article was commissioned by the Guest Editors (Drs. Richard D. Sontheimer, M. Kari Connolly, David F. Fiorentino, and Victoria P. Werth) for the series "Rheumatologic Skin Disease" published in Annals of Translational Medicine. The article has undergone external peer review.

Reporting Checklist: The authors have completed the narrative review reporting checklist. Available at http:// dx.doi.org/10.21037/atm-20-5185

Conflicts of Interest: All authors have completed the ICMJE uniform disclosure form (available at http://dx.doi. org/10.21037/atm-20-5185). The series "Rheumatologic Skin Disease" was commissioned by the editorial office without any funding or sponsorship. The authors have no other conflicts of interest to declare.

Ethical Statement: The authors are accountable for all aspects of the work in ensuring that questions related to the accuracy or integrity of any part of the work are appropriately investigated and resolved.

Open Access Statement: This is an Open Access article distributed in accordance with the Creative Commons Attribution-NonCommercial-NoDerivs 4.0 International License (CC BY-NC-ND 4.0), which permits the noncommercial replication and distribution of the article with the strict proviso that no changes or edits are made and the original work is properly cited (including links to both the formal publication through the relevant DOI and the license). See: https://creativecommons.org/licenses/by-nc-nd/4.0/.

\section{References}

1. Nguyen AV, Soulika AM. The Dynamics of the Skin's Immune System. Int J Mol Sci 2019;20:1811.

2. Kabashima K, Honda T, Ginhoux F, et al. The immunological anatomy of the skin. Nat Rev Immunol 2019;19:19-30.

3. Clark RA, Chong B, Mirchandani N, et al. The vast majority of CLA+ T cells are resident in normal skin. J Immunol 2006;176:4431-9.

4. Bos JD, Zonneveld I, Das PK, et al. The skin immune system (SIS): distribution and immunophenotype of lymphocyte subpopulations in normal human skin. J Invest Dermatol 1987;88:569-73.

5. Egbuniwe IU, Karagiannis SN, Nestle FO, et al. Revisiting the role of $\mathrm{B}$ cells in skin immune surveillance. Trends Immunol 2015;36:102-11.

6. Debes GF, McGettigan SE. Skin-Associated B Cells in Health and Inflammation. J Immunol 2019;202:1659-66.

7. Mestas J, Hughes CC. Of mice and not men: differences between mouse and human immunology. J Immunol 2004;172:2731-8.

8. Geherin SA, Fintushel SR, Lee MH, et al. The skin, a novel niche for recirculating B cells. J Immunol 2012;188:6027-35.

9. Wilson RP, McGettigan SE, Dang VD, et al. IgM Plasma Cells Reside in Healthy Skin and Accumulate with Chronic Inflammation. J Invest Dermatol 2019;139:2477-87.

10. Saul L, Ilieva KM, Bax HJ, et al. IgG subclass switching and clonal expansion in cutaneous melanoma and normal skin. Sci Rep 2016;6:29736.

11. Zhou S, Liu Z, Yuan H, et al. Autoreactive B Cell Differentiation in Diffuse Ectopic Lymphoid-Like Structures of Inflamed Pemphigus Lesions. J Invest Dermatol 2020;140:309-318.e8.

12. Metze D, Kersten A, Jurecka W, et al. Immunoglobulins coat microorganisms of skin surface: a comparative immunohistochemical and ultrastructural study of cutaneous and oral microbial symbionts. J Invest Dermatol 1991;96:439-45.

13. Okada T, Konishi H, Ito M, et al. Identification of secretory immunoglobulin A in human sweat and sweat 


\section{Page 8 of 9}

glands. J Invest Dermatol 1988;90:648-51.

14. Metze D, Jurecka W, Gebhart W, et al.

Immunohistochemical demonstration of immunoglobulin A in human sebaceous and sweat glands. J Invest Dermatol 1989;92:13-7.

15. Iyer AM, Mohanty KK, van Egmond D, et al. Leprosyspecific B-cells within cellular infiltrates in active leprosy lesions. Hum Pathol 2007;38:1065-73.

16. Cruz AR, Ramirez LG, Zuluaga AV, et al. Immune evasion and recognition of the syphilis spirochete in blood and skin of secondary syphilis patients: two immunologically distinct compartments. PLoS Negl Trop Dis 2012;6:e1717.

17. Dantas ML, Oliveira JM, Carvalho L, et al. Comparative analysis of the tissue inflammatory response in human cutaneous and disseminated leishmaniasis. Mem Inst Oswaldo Cruz 2014;109:202-9.

18. Timmermans WM, van Laar JA, van Hagen PM, et al. Immunopathogenesis of granulomas in chronic autoinflammatory diseases. Clin Transl Immunology 2016;5:e118.

19. Ahmed AA, Nordlind K, Schultzberg M, et al. Interleukin-1 alpha- and beta-, interleukin-6- and tumour necrosis factor-alpha-like immunoreactivities in chronic granulomatous skin conditions. Acta Derm Venereol 1994;74:435-40.

20. Saldanha MG, Queiroz A, Machado PRL, et al. Characterization of the Histopathologic Features in Patients in the Early and Late Phases of Cutaneous Leishmaniasis. Am J Trop Med Hyg 2017;96:645-52.

21. Erdag G, Schaefer JT, Smolkin ME, et al. Immunotype and immunohistologic characteristics of tumor-infiltrating immune cells are associated with clinical outcome in metastatic melanoma. Cancer Res 2012;72:1070-80.

22. Ladanyi A, Kiss J, Mohos A, et al. Prognostic impact of B-cell density in cutaneous melanoma. Cancer Immunol Immunother 2011;60:1729-38.

23. Helmink BA, Reddy SM, Gao J, et al. B cells and tertiary lymphoid structures promote immunotherapy response. Nature 2020;577:549-55.

24. Cabrita R, Lauss M, Sanna A, et al. Tertiary lymphoid structures improve immunotherapy and survival in melanoma. Nature 2020;577:561-5.

25. Bosisio FM, Wilmott JS, Volders N, et al. Plasma cells in primary melanoma. Prognostic significance and possible role of IgA. Mod Pathol 2016;29:347-58.

26. Affara NI, Ruffell B, Medler TR, et al. B cells regulate macrophage phenotype and response to chemotherapy in squamous carcinomas. Cancer Cell 2014;25:809-21.
Lerman et al. Human cutaneous B cells: what do we really know?

27. Fogarty GB, Bayne M, Bedford P, et al. Three cases of activation of cutaneous squamous-cell carcinoma during treatment with prolonged administration of rituximab. Clin Oncol (R Coll Radiol) 2006;18:155-6.

28. Strobel SB, Safferling K, Lahrmann B, et al. Altered density, composition and microanatomical distribution of infiltrating immune cells in cutaneous squamous cell carcinoma of organ transplant recipients. Br J Dermatol 2018;179:405-12.

29. Kobayashi T, Oishi K, Okamura A, et al. Regulatory B1a Cells Suppress Melanoma Tumor Immunity via IL-10 Production and Inhibiting T Helper Type 1 Cytokine Production in Tumor-Infiltrating CD8+ T Cells. J Invest Dermatol 2019;139:1535-1544.e1.

30. Geherin SA, Gomez D, Glabman RA, et al. IL-10+ Innate-like B Cells Are Part of the Skin Immune System and Require alpha4beta1 Integrin To Migrate between the Peritoneum and Inflamed Skin. J Immunol 2016;196:2514-25.

31. Yang X, Yang J, Chu Y, et al. T follicular helper cells and regulatory $\mathrm{B}$ cells dynamics in systemic lupus erythematosus. PLoS One 2014;9:e88441.

32. Lund FE. Cytokine-producing B lymphocyteskey regulators of immunity. Curr Opin Immunol 2008;20:332-8.

33. Yuan H, Zhou S, Liu Z, et al. Pivotal Role of Lesional and Perilesional T/B Lymphocytes in Pemphigus Pathogenesis. J Invest Dermatol 2017;137:2362-70.

34. Harrist TJ, Mihm MC Jr. The specificity and clinical usefulness of the lupus band test. Arthritis Rheum 1980;23:479-90.

35. Hussein MR, Aboulhagag NM, Atta HS, et al. Evaluation of the profile of the immune cell infiltrate in lichen planus, discoid lupus erythematosus, and chronic dermatitis. Pathology 2008;40:682-93.

36. Xie Y, Jinnin M, Zhang X, et al. Immunohistochemical characterization of the cellular infiltrate in discoid lupus erythematosus. BioScience Trends 2011;5:83-8.

37. Thorpe RB, Gray A, Kumar KR, et al. Site-specific analysis of inflammatory markers in discoid lupus erythematosus skin. ScientificWorldJournal 2014;2014:925805.

38. Kogame T, Yamashita R, Hirata M, et al. Analysis of possible structures of inducible skin-associated lymphoid tissue in lupus erythematosus profundus. J Dermatol 2018;45:1117-21.

39. O'Brien JC, Hosler GA, Chong BF. Changes in T cell and B cell composition in discoid lupus erythematosus skin at different stages. J Dermatol Sci 2017;85:247-9. 
40. Dey-Rao R, Sinha AA. In silico Analyses of Skin and Peripheral Blood Transcriptional Data in Cutaneous Lupus Reveals CCR2-A Novel Potential Therapeutic Target. Front Immunol 2019;10:640.

41. Roumm AD, Whiteside TL, Medsger TA Jr, et al. Lymphocytes in the skin of patients with progressive systemic sclerosis. Quantification, subtyping, and clinical correlations. Arthritis Rheum 1984;27:645-53.

42. Bosello S, Angelucci C, Lama G, et al. Characterization of inflammatory cell infiltrate of scleroderma skin: B cells and skin score progression. Arthritis Res Ther 2018;20:75.

43. Whitfield ML, Finlay DR, Murray JI, et al. Systemic and cell type-specific gene expression patterns in scleroderma skin. Proc Natl Acad Sci U S A 2003;100:12319-24.

44. Streicher K, Sridhar S, Kuziora M, et al. Baseline Plasma Cell Gene Signature Predicts Improvement in Systemic Sclerosis Skin Scores Following Treatment With Inebilizumab (MEDI-551) and Correlates With Disease Activity in Systemic Lupus Erythematosus and Chronic Obstructive Pulmonary Disease. Arthritis Rheumatol 2018;70:2087-95.

45. Francois A, Chatelus E, Wachsmann D, et al. B lymphocytes and B-cell activating factor promote collagen and profibrotic markers expression by dermal fibroblasts in systemic sclerosis. Arthritis Res Ther 2013;15:R168.

46. van der Zee HH, de Ruiter L, Boer J, et al. Alterations in leucocyte subsets and histomorphology in normalappearing perilesional skin and early and chronic hidradenitis suppurativa lesions. Br J Dermatol 2012;166:98-106.

47. Hoffman LK, Tomalin LE, Schultz G, et al. Integrating the skin and blood transcriptomes and serum proteome in hidradenitis suppurativa reveals complement dysregulation and a plasma cell signature. PLoS One 2018;13:e0203672.

48. Czarnowicki T, Gonzalez J, Bonifacio KM, et al. Diverse activation and differentiation of multiple B-cell subsets in patients with atopic dermatitis but not in patients with psoriasis. J Allergy Clin Immunol 2016;137:118-129.e5.

49. Joly P, Mouquet H, Roujeau JC, et al. A single cycle of rituximab for the treatment of severe pemphigus. N Engl J Med 2007;357:545-52.

50. Vinay K, Kanwar AJ, Mittal A, et al. Intralesional Rituximab in the Treatment of Refractory Oral Pemphigus Vulgaris.

Cite this article as: Lerman I, Mitchell DC, Richardson CT. Human cutaneous B cells: what do we really know? Ann Transl Med 2021;9(5):440. doi: 10.21037/atm-20-5185
JAMA Dermatol 2015;151:878-82.

51. Iraji F, Danesh F, Faghihi G, et al. Comparison between the efficacy of intralesional rituximab versus intralesional triamcinolone in the treatment refractory Pemphigus Vulgaris lesions: A randomized clinical trial. Int Immunopharmacol 2019;73:94-7.

52. Vital EM, Wittmann M, Edward S, et al. Brief report: responses to rituximab suggest $\mathrm{B}$ cell-independent inflammation in cutaneous systemic lupus erythematosus. Arthritis Rheumatol 2015;67:1586-91.

53. Quelhas da Costa R, Aguirre-Alastuey ME, Isenberg DA, et al. Assessment of Response to B-Cell Depletion Using Rituximab in Cutaneous Lupus Erythematosus. JAMA Dermatol 2018;154:1432-40.

54. Raderer M, Jager G, Brugger S, et al. Rituximab for treatment of advanced extranodal marginal zone B cell lymphoma of the mucosa-associated lymphoid tissue lymphoma. Oncology 2003;65:306-10.

55. Vashisht P, Borghoff K, O'Dell JR, et al. Belimumab for the treatment of recalcitrant cutaneous lupus. Lupus 2017;26:857-64.

56. Chong BF, Tseng LC, Kim A, et al. Differential expression of BAFF and its receptors in discoid lupus erythematosus patients. J Dermatol Sci 2014;73:216-24.

57. Gordon JK, Martyanov V, Franks JM, et al. Belimumab for the Treatment of Early Diffuse Systemic Sclerosis: Results of a Randomized, Double-Blind, Placebo-Controlled, Pilot Trial. Arthritis Rheumatol 2018;70:308-16.

58. Lafyatis R, Kissin E, York M, et al. B cell depletion with rituximab in patients with diffuse cutaneous systemic sclerosis. Arthritis Rheum 2009;60:578-83.

59. Smith V, Piette Y, van Praet JT, et al. Two-year results of an open pilot study of a 2 -treatment course with rituximab in patients with early systemic sclerosis with diffuse skin involvement. J Rheumatol 2013;40:52-7.

60. Takahashi K, Yanagi T, Kitamura S, et al. Successful treatment of hidradenitis suppurativa with rituximab for a patient with idiopathic carpotarsal osteolysis and chronic active antibody-mediated rejection. J Dermatol 2018;45:e116-e117.

61. Simon D, Hosli S, Kostylina G, et al. Anti-CD20 (rituximab) treatment improves atopic eczema. J Allergy Clin Immunol 2008;121:122-8. 